\section{Physical Instrumentation in Medicine and Biology}

By D. J. Dewhurst. Pp. xii +205 , illustrated. Oxford, London etc.: Pergamon Press. 1966. 60s.

This book is based upon the author's experience in providing a practical and theoretical course in electronic instrumentation for medical and biological graduates in the University of Melbourne. The course was also used to reorient those with an electronic training to the problems peculiar to biological work. The course outlined emphasises the need to maintain a practical: theoretical ratio of $3: 1$ hours per session and each chapter of the book includes suggestions for further reading, together with a series of practical exercises. The latter culminate in the construction of equipment such as an oscilloscope, a biologioal preamplifier and a gamma radiation detector.

The theoretical introduction to the subject of electronics and the account of basic circuitry is well undertaken and includes descriptions of amplifiers, power supplies and the oscilloscope. The second half of the book is concerned with circuits of biological interest. Special reference is made to the various types of multivibrator and devices for stimulating and recording from tissues; ratemeters, scalers and transducers are also discussed. Great mathematical ability which most medical and biological graduates seem to lack, is not assumed, although some basic mathematical ideas are inevitably included. A welcome feature is the inclusion of actual photographs of circuit construction and wiring. Although the practical exercises could be undertaken alone, the greatest benefit would be derived in performing them in an organised class.

The book is well printed and is both enjoyable and informative to read, and will be sympathetically received by the growing numbers of those who seek, without formal training, to build or understand apparatus of this type.

\section{The Chromosome Disorders}

By G. H. Valentine. Pp. $x+129$ illustrated. London: Heinemann. 1966. 25s.

It is perhaps trite to comment on the recent spate of publications concerning discoveries in the field of cytogenetics; however, advances have been made with such rapidity that the chromosome count has become almost a service rather than a research procedure. Clinicians and students who have attempted to gain an outline knowledge of the subject have been hampered by the lack of any suitable introduction text is both up to date and intelligible. This book is written not by a cytogenecist but by a practising paediatrioian who has attempted to provide a "story book" guide through the jungle of neologism and jargon that daunt the uninitiated to this subject.

The first chapters are devoted to descriptions of normal and abnormal cell division and they are illustrated with photographs and diagrams. Subsequent chapters include descriptions of all the commonly encountered abnormalities and include sections on mongolism, D, and E trisomies, Turner's and Klinefelter's syndromes together with reference to the problems of mosaicism and polysomy.

Of particular interest and value is the chapter devoted to dermatoglyphics which have recently assumed importance in genetics in addition to their role in criminology.

The author has commendably refrained from any attempt to provide detailed references with the re- sult that the text is unbroken by the names and numbers that detract from so many modern textbooks, a short suggested list of works for further reading has been included however. The book is well printed and produced and at its present price represents good value for those seeking an introduction to this subject.

Organisation for Protein Biosynthesis

By Alan Wiseman. Pp. ix +217 illustrated. Oxford: Blackwell. 1965. 45s.

This book is intended for students of biochemistry, microbiology and physiology and also as a work of reference and entreé to the literature for works in related fields. Basic ideas concerning the molecular structure of proteins and nucleic acids are outlined in the introduction. The remainder of the work is divided into four major sections: "The Biochemical Mechanisms in the 'Classical Scheme' of Protein Biosynthesis', 'The Specificity and Controlling Mechanisms of Enzyme Biosynthesis', 'The Regulation of Enzyme Biosynthesis' and 'Other Pathways of Protein Biosynthesis'.

In the first section the formation of activated amino-acids is described and related to the role of transfer R.N.A. as an acceptor for these. The structure and function to the ribosomes is discussed. The second section outlines the funotions of D.N.A. and messenger R.N.A. and indicates the progress that has been made in the elucidation of the genetic coding sequences for each amino-acid. Induced enzyme synthesis and the factors which modify it is discussed in the third section with regard to micro-organisms and the animal tissues. The final section deals with protein synthesis in cellular organelles other than the cytoplasmic ribosomes and examines the evidence for the existence of activated peptides.

A slightly unusual feature at the end of each chapter is the inclusion of three brief sections, a summary, a note of recent developments and an outline of anticipated future trends. While there may be a case for summaries, it is difficult to justify the separation of recent developments in a work which by its nature must attempt to present the most recently available information.

The book is on the whole readable and adequately printed and produced. Centainly it contains a wealth of information together with over three hundred references. It will be invaluable for those entering the field of protein biochemistry although its appeal to medical graduates will be limited.

\section{Cytological Diagnosis in Medical Practice}

By J. BAMFORTH. Pp. 246 illustrated. London: J. \& A. Churchill. 1966. 100 s.

The appearance of a new book devoted solely to cytological diagnosis is just cause for comment. The more so when its author is one so long associated with cytology from Dudgeon to the present day.

Throughout the book which is well produced and lavishly illustrated by excellent black and white photomicrographs, emphasis is placed on histological confirmation of cytological findings. Indeed at times this point is over-emphasised and many of the histological illustrations could have been omitted without destroying this accepted premise and with a considerable reduction in cost, ninety-one of the 298 illustrations being of histological material. 